\title{
O Raciocínio Computacional para a Educação Básica: considerações sobre o ensino de Análise Combinatória e Probabilidade
}

\author{
Conceição A. G. Tavares ${ }^{1,2}$, Lais N. Salvador ${ }^{1,2}$, Denise N. Viola ${ }^{1}$ \\ ${ }^{1}$ Instituto de Matemática e Estatística - Universidade Federal da Bahia/UFBA \\ ${ }^{2}$ PGCOMP - Programa de Pós-graduação em Ciência da Computação \\ Av. Adhemar de Barros, s/n - CEP 40.170-110 - Salvador - BA - Brasil \\ conceicaotava@gmail.com, \{laisns, viola\}@ufba.br
}

\begin{abstract}
The article presents a reflection on the influence of Computational Thinking in the teaching-learning of Statistical concepts, through workshops in the constructivist and computational environments, with the use of software $R$ as calculator and in the use of algorithms. The workshop had activities applied to teachers of the Basic Public Education of Bahia and to the undergraduate students in Mathematics at UFBA. The results point out both the interest in the application of methodologies as a pedagogical resource and the lack of knowledge about the subject by both groups. The work with the constructivist models and the software $R$ showed that the experimentation, the commands and the applications of the formulas can be significant for the learning.
\end{abstract}

Resumo. $O$ artigo apresenta uma reflexão sobre a influência do Pensamento Computacional no ensino-aprendizagem de conceitos de Estatística, por meio de oficinas nos ambientes construtivista e computacional, com o uso do software $R$ como calculadora e no uso de algoritmos. A oficina teve atividades aplicadas aos professores da Educação Básica pública da Bahia e para os alunos de licenciatura em Matemática da UFBA. Os resultados apontam tanto o interesse na aplicação das metodologias como recurso pedagógico, quanto o desconhecimento sobre o assunto por parte de ambos os grupos selecionados. O trabalho com os modelos construtivista e o software $R$ mostrou que a experimentação, os comandos e as aplicações das fórmulas podem ser significativos para a aprendizagem.

\section{Introdução}

Os tópicos de Estatística, estão incluídos, por determinação dos Parâmetros Curriculares Nacionais (PCN), no bloco "Tratamento da Informação", que é um dos cinco blocos de conteúdos conceituais e procedimentos para o ensino da Matemática. Os tópicos relativos à Estatística na Educação Básica estão presentes nos $8^{\circ}$ e $9^{\circ}$ anos (final do Ensino Fundamental II) e no $2^{\circ}$ ano do Ensino Médio.

Apesar desta determinação, a Estatística, segundo [Cazorla and SANTANA 2006], ainda é vista timidamente na Educação Básica. Ensina-se, na maioria das vezes, apenas com recursos tradicionais. Além disso, há o agravante da disposição dos seus conteúdos programáticos aparecerem nos últimos 
VI Congresso Brasileiro de Informática na Educação (CBIE 2017)

Anais do XXIII Workshop de Informática na Escola (WIE 2017)

tópicos dos livros didáticos adotados e, muitas vezes, não serem ensinados aos alunos, conforme elucida o autor [PANAINO 1998].

Ainda segundo [PANAINO 1998], a Estatística foi introduzida em 1988 no currículo escolar brasileiro da Educação Básica, a partir da publicação dos PCN, que determinam que ela deva ser ensinada durante o Ensino Fundamental e Médio nas aulas de Matemática, desde as séries iniciais.

Apesar disso os conteúdos de Estatística não são trabalhados ou, em alguns casos, sequer vistos em sala de aula,mas por outro lado, são exigidos em exames oficiais que medem a aprendizagem dos alunos através de avaliações nacionais como: a Prova Brasil, as Olimpíadas Brasileiras de Matemática das Escola Públicas (OBMEP), as Olimpíadas Brasileiras de Matemática (OBM) e o Exame Nacional de Ensino Médio (ENEM).

O resultado destas avaliações nacionais aponta um déficit neste conteúdo, o que gerou a motivação para trabalhar com os conceitos de Análise Combinatória e Probabilidade em duas diferentes perspectivas: com professores da Educação Básica pública da Bahia e com os alunos da licenciatura em Matemática da Universidade Federal da Bahia - UFBA.

Para isso, foi proposta a oficina "Análise Combinatória e Probabilidade", com o objetivo de apresentar métodos e recursos didáticos não convencionais aos professores da rede pública e aos alunos da Licenciatura em Matemática, frente às necessidades vistas na relação ensino-aprendizagem. Assim, a oficina surgiu como uma atividade de extensão do Instituto de Matemática e Estatística - IME/ UFBA.

Este artigo tem por objetivo apresentar o modus operandi de uma oficina desenvolvida sobre um tema pouco trabalhado em aulas de matemática do ensino básico público da Bahia - Ensino Fundamental e Médio - além de avaliar as preferências dos professores no uso das metodologias para o ensino de Análise Combinatória e Probabilidade. Relatar os resultados visíveis da aplicação da Oficina de Análise Combinatória e Probabilidade com professores da Educação Básica é, também, compreender os caminhos do ensino matemático na contemporaneidade com o intuito de buscar soluções exequíveis. Para tanto, a seção 2 trará conceitos fundamentais sobre o Raciocínio Computacional e o Software $\mathrm{R}$ atrelado à noção educacional de construtivismo, que podem ser compreendidos como os suportes teóricos deste trabalho. Em sequência, a Seção 3 exibirá a metodologia de desenvolvimento da oficina e a seção 4 apresentará, em forma de reflexão, os resultados de sua aplicação entre os dois públicos selecionados.

\section{Pensamento/Raciocínio Computacional}

No artigo de [Wing 2006] incluso no periódico Communications of the ACM, vemos vários exemplos de como aspectos da Ciência da Computação estão presentes na vida cotidiana e poderiam ser ensinados a crianças e adolescentes, de forma a possibilitar uma melhor compreensão de um mundo permeado por dispositivos computacionais. Wing define o termo "Pensamento Computacional" para se referir ao conjunto de competências e habilidades da Computação que podem ser úteis em outras áreas do conhecimento, através de conceitos como abstração, decomposição, entre outros. No mesmo trabalho o Pensamento Computacional também é apresentado como uma metodologia de resolução de problemas que expande o domínio da informática em todas as disciplinas, proporcio- 
nando um distinto meio de análise e desenvolvimento de soluções para os problemas que podem ser resolvidos computacionalmente, com foco na captação, automação e análise.

Para [Brackmann et al. 2016], o Pensamento Computacional utiliza quatro técnicas ou habilidades, também conhecidos como pilares, para alcançar o objetivo principal desta abordagem na solução de problemas. Todos os quatro pilares (decomposição, reconhecimento de padrões, abstração e algoritmo), têm grande relevância e são independentes durante o processo de formulação de soluções computacionalmente viáveis.

Por outro lado, [Ferreira et al. 2015] denomina o Pensamento Computacional como Raciocínio Computacional e diz que esse último é utilizado, de forma mais específica, que o Pensamento Computacional está relacionado ao pensamento analítico e ao raciocínio dedutivo - que envolve a lógica e a matemática. Portanto, podemos compreender o raciocínio computacional como a capacidade de resolução de problemas de forma sistemática, usando habilidades como organização e análise de dados, construção de algoritmos, abstração, criação de modelos, simulação, dedução e abstração. Diante disso, usaremos o termo Raciocínio Computacional (RC) como representativo do Pensamento Computacional.

Na prática profissional, observa-se que é preciso levar ao aluno a oportunidade de conhecer outros métodos de resolver problemas, por exemplo, para reduzir problemas grandes e aparentemente insolúveis em problemas menores e mais simples de resolver, que é uma das habilidades do Raciocínio Computacional. Para isso, os professores devem pensar de forma abstrata e em múltiplos níveis, por exemplo, com o uso de recursos como computadores e modelos construtivistas para a resolução de problemas, e entender como novos métodos podem motivar os alunos inserindo atividades que exploram as competências e habilidades do RC.

\subsection{O Software $R$ e o Construtivismo}

Diferentes estratégias podem ser adotadas para o ensino de Estatística na Educação Básica. Uma das opções é oapoio de algum software como calculadora ou no desenvolvimento de algoritmos através de linguagem de programação para auxiliar na resolução de problemas, na visualização dos resultados ou na decisão de qual fórmula estatística utilizar.

Para os estatísticos, o software $\mathrm{R}^{1}$ é especialmente útil porque contem diversos mecanismos incorporados para a organização de dados, execução de cálculos sobre informações e criação de representações gráficas de conjuntos de dados. Outro fator relevante para a sua escolha é a sua facilidade pois não é preciso saber programar para usá-lo, é apenas necessário entender seu funciomento básico e o ambiente de linhas de comando, conforme explicita [da Serra Costa et al. 2011].

Mais que uma tendência, a Informática na Estatística constitui uma realidade. Tal condição, contudo, somente pode ser viabilizada se a capacidade que a tecnologia tem de atuar como um facilitador no entendimento e na compreensão dos conceitos envolvidos no problema e suas aplicações for efetivamente praticada.

Além de escolher o software para a montagem da oficina, é necessário também refletir sobre sua aplicação e sobre a prática docente neste processo, ou seja, paralelamente

\footnotetext{
${ }^{1}$ https://www.r-project.org/
} 
VI Congresso Brasileiro de Informática na Educação (CBIE 2017)

Anais do XXIII Workshop de Informática na Escola (WIE 2017)

ao uso do software fez-se necessário uma comparação entre tipos de ensino e métodos. Com isso, chegou-se ao conceito de construtivismo.

O construtivismo nasce do pensamento de Piaget, que estimula uma forma de pensar onde o aprendiz, em vez de assimilar o conteúdo passivamente, reconstrói o conhecimento existente, promovendo a mudança a que denominamos aprendizagem. Neste esteio, por meio dos conceitos de [Papert 1980], criador do construcionismo que propôs o uso do computador segundo essa abordagem nos modelos, criando uma relação dialética entre o pensamento abstrato e o concreto, que se refere às suas ideias "concretizadas"pelo computador. Assim, compreende-se que o construtivismo necessita do uso de material concreto denominado "modelo", que auxilia as situações nas quais os alunos constroem conhecimento com o suporte do computador.

Nesta metodologia é o aluno que deve ser colocado como elemento principal da construção do conhecimento, ficando o professor como mediador/facilitador. O professor tem a função de colocar o estudante diante de situações (práticas ou teóricas) para que estes encontrem soluções e construam o conhecimento. Assim, a experiência de vida do aluno e seus conhecimentos anteriormente adquiridos são de fundamental importância. Ao docente cabe também a função de incentivar os alunos na busca por novos conhecimentos e na aprendizagem de novos conceitos, tendo a oportunidade de escolha de qual método é o mais apropriado para o momento do aluno, para construir o aprendizado a partir de conhecimentos e/ou conceitos anteriores.

A aplicação da metodologia construtivista com o apoio do Software R serviu como base para a proposição da oficina nos dois diferentes momentos previstos. Antes, no entanto, de apresentar o modelo e a execução da oficina, faz-se necessário considerar um trabalho correlato de suma importância. Em pesquisa semelhante, Ferreira (2011) em "Ensino de Probabilidade com o uso do programa estatístico R numa perspectiva construcionista", investigou a aprendizagem de conceitos probabilísticos nos ambientes papel e lápis e computacional (software R), sob a perspectiva do letramento probabilístico de Gal e do construcionismo de Papert. O autor aponta que a maior autonomia dos alunos na construção de seu conhecimento está atrelada ao uso do recurso computacional, constituindo uma importante ferramenta para a construção do conhecimento probabilístico com uma perspectiva construcionista, e que o uso do software $\mathrm{R}$ corresponde às expectativas propostas. Apesar de todas as dificuldades detectadas, tanto no que se refere ao entendimento do conceito probabilístico, quanto no nível de autonomia dos alunos, o autor acredita, que apesar deste tipo de trabalho ainda não ser comum no cotidiano escolar, que a experiência proporcionou aos alunos reflexões mais abrangentes em relação ao conceito de probabilidade por meio de uma visão diferenciada do uso do computador com o uso do software R. O autor também apontou a necessidade de estudos posteriores que reforcem ou dialoguem com os resultados por ele alcançados.

\section{Metodologia de Desenvolvimento das Oficinas}

A proposta foi associar o Raciocínio Computacional à linguagem de programação com a utilização do software $\mathrm{R}$ no desenvolvimento de algoritmo ou como calculadora, para auxílio na resolução de problemas. A esta base associa-se o construtivismo e os "modelos" concretos propostos durante a oficina, numa investigação empírica, com o intuito de avaliar se essa relação pode contribuir para sanar as possíveis dificuldades encontradas 
pelos professores e alunos da licenciatura, que são professores em formação, no tocante ao ensino e aprendizagem dos tópicos de Análise Combinatória e Probabilidade.

As oficinas ocorreram em 2016 e 2017, utilizando a metodologia Delineamento em Quadrado Latino (DQL) ${ }^{2}$. O DQL é utilizado quando existem fatores em duas direções e pretende-se tirar esse efeito, diminuindo, assim, a taxa de erro e assumindo que os fatores não vão interagir no processo. Por exemplo, ordem do exercício x dificuldade [PIMENTEL-GOMES 1990].

O DQL é utilizado quando um fator precisa ser modificado por outras duas fontes conhecidas, reduzindo assim o efeito da ordem da metodologia de ensino utilizada. Nesse método, há rodízio de turmas e de conceitos que recebem o mesmo tratamento. Os tratamentos são distribuídos de forma que cada integrante/grupo participe uma única vez em cada ambiente onde foram aplicadas as metodologias e que cada indivíduo participe de todas elas.

As oficinas foram realizadas, nas dependências do IME - UFBA Instituto de Matemática e Estatística. A metodologia utilizada buscou propiciar a discussão de temas importantes do dia a dia de trabalho dos alunos de graduação (PIBID ou licenciatura) e dos professores da rede pública. Aplicou-se conceitos de Construtivismo como processo metodológico no qual utilizou-se material concreto, os "modelos" e a linguagem de programação com a utilização do software R para a associação dos conceitos estatísticos relacionado ao RC (computação), todos tendo como base os conceitos do método tradicional.

Outra questão relevante foi a discussão sobre como os professores realizavam seu trabalho e a contínua reflexão das ações no decorrer da oficina para que repensassem suas metodologias de ensino. Nossa perspectiva era que, após a oficina, os professores pudessem avaliar e ter a oportunidade para apresentar a seus alunos novas metodologias, proporcionando atividades lúdicas, simplificando os processos tradicionais, criando meios alternativos de resolução dos mesmos exercícios,com metodologias distintas e assim, permitir a escolha do método mais adequado, com processos de decisão individual $\mathrm{e}$, consequentemente, favorecer a aprendizagem.

Aos professores em exercício na educação básica pública da Bahia, a oficina serviria para ampliar o leque de opções didáticas, apresentar aulas diferenciadas e, deste modo, possibilitar melhores resultados dos alunos nas avaliações nacionais. E, em relação aos graduandos, mostrar como podem aplicar técnicas distintas para o ensino e resolução de conteúdos estatísticos, sobretudo como recurso para as aulas ministradas por eles nos estágios.

\subsection{Experimento: Oficina de Análise Combinatória e Probabilidade}

A oficina iniciou-se com um convite aberto aos alunos de licenciatura de Matemática da UFBA, estagiários do Programa Instituição de Bolsas de Iniciação à Docência (PIBID) e aos professores de matemática da Educação Básica pública da Bahia. Para isso foi usada uma lista de e-mail adquirida através da Formação Continuada PAFOR, apresentando a proposta das oficinas, o plano de trabalho, o local, a data, os horários e o número de

\footnotetext{
${ }^{2}$ Um quadrado latino de ordem $\mathrm{n}$ é uma matriz ( $\mathrm{x} \mathrm{n}$ ) preenchida com $\mathrm{n}$ diferentes símbolos de tal maneira que ocorrem no máximo uma vez em cada linha ou coluna.
} 
vagas. Os interessados deveriam fazer sua inscrição via e-mail . Para os professores o dia escolhido foi uma quarta-feira, devido à disponibilidade para atividades complementares, para os alunos foi uma quinta-feira, dia destinado às atividades do PIBID. Salienta-se que o único pré-requisito para participação era ser atuante como professor de matemática na Educação Básica pública da Bahia ou estar devidamente matriculado na instituição UFBA. Essa oficina foi gratuita e forneceu certificado.

Foram selecionados na primeira oficina 43 professores de matemática, com duração de $8 \mathrm{~h}$. Ao chegarem ao IME, todos assinaram o Termo de Consentimento Livre e Esclarecido (TCLE) e iniciaram as dinâmicas sem prévio conhecimento das técnicas e do que era esperado deles. Responderam 2 questões, adaptadas dos bancos de dados das avaliações nacionais (ENEM, OBEMEP, Prova Brasil) sobre Análise Combinatória e Probabilidade, com o objetivo de analisar e verificar o conhecimento prévio de cada participante, utilizando a metodologia tradicional.

A seguir foi apresentado através de slides o tema trabalhado utilizando a metodologia tradicional, mostrando as fórmulas principais do assunto e exercícios já resolvidos, neste momento os participantes só observaram. Após isso, foi pedido que fizessem a resolução de outros problemas com apoio de material concreto os "modelos", utilizando a metodologia construtivista para entender o raciocínio lógico dos participantes. A próxima etapa foi a apresentação do software R, sua interface e seus comandos básicos no laboratório de informática. Durante estas atividades os participantes receberam uma folha em branco para que escrevessem as impressões que estavam tendo da oficina e suas expectativas. No período da tarde a oficina foi aplicada segundo o método DQL: foi feito um rodízio dos participantes por meio de sorteio no software $\mathrm{R}$, de modo que fossem criados 3 grupos de professores, denominados $P_{1}, P_{2}$ e $P_{3}$ (compostos por uma média de 14 participantes). Foram separados os grupos e dadas instruções de como ocorreria a Oficina no sentido de que fariam rodízios sem prévias instruções sobre a metodologia que seria aplicada em cada etapa.

As questões propostas tinham igual grau de dificuldade e foram adaptadas dos bancos de dados das avaliações nacionais. Elas foram previamente resolvidas pela equipe responsável e deveriam ser respondidas ao mesmo tempo pelos 3 grupos, utilizando a metodologia referente à sala que se encontrava o participante, num intervalo de 1 hora (50 minutos para cada questão e 10 minutos para troca de ambiente) conforme rodízio. Assim tivemos: $P_{1}, P_{2}$ e $P_{3}$ grupos de professores, participando de 3 metodologias (ensino tradicional, construtivismo e linguagem de programação com o software R) em 2 salas e 1 laboratório de computação, respondendo grupos de questões $Q_{3,4}, Q_{5,6}$ e $Q_{7}, 8$, referentes à Análise Combinatória e Probabilidade, retiradas das avaliações nacionais.

A confecção dos modelos concretos para a Metodologia Construtivista foi apoiada pelos alunos do projeto de pesquisa de Laboratório de Ensino de Matemática (LEMA), com materiais reciclados e/ou baixo custo, feitos a partir de impressão em papel A4.

A aplicação do software R como calculadora se deu mediante o uso das operações aritméticas básicas $\left(+,-,{ }^{*}, /\right)$, e os comandos: combn $(\mathrm{x}, \mathrm{y})$ mostra as combinações possíveis, choose $(\mathrm{x}, \mathrm{y})$ mostra o número de combinações, e factorial(x): fatorial do número $\mathrm{x}$, onde $(\mathrm{x}, \mathrm{y})$ são os valores dados nas questões a serem calculados.

Instalados os grupos em suas respectivas salas/laboratório, foi explicado qual era 
a metodologia referente àquele espaço,sendo a mesma questão aplicada em todos os ambientes. Um grupo devia resolver com a metodologia tradicional (resolução a partir de fórmulas), o outro resolver a questão com a metodologia Construtivista com uso do entendimento feito a partir do material concreto e manuseio dos modelos. E no laboratório de informática um terceiro grupo resolvia as questões com comandos dos software R, e ao final foi solicitado que o participante salvasse os cálculos feitos e enviasse por e-mail os resultados para a comissão da oficina.

Dado início ao rodízio o procedimento sucedeu até que todos os grupos de professores participassem de todas as metodologias e respondessem todas as questões propostas.

Uma síntese dos principais aspectos do delineamento DQL, evidenciando o ambiente e a metodologia no qual cada etapa foi desenvolvida, pode ser observada na Tabela 1:

Tabela 1. Sorteio da ordem dos participantes na oficina utilizando o DQL

\begin{tabular}{c|c|c|c}
\hline $\begin{array}{c}G_{1}-\text { Met. } \\
\text { Tradicional }\end{array}$ & $\begin{array}{c}G_{2}-\text { Met. } \\
\text { Construtivista }\end{array}$ & $\begin{array}{c}G_{3}-\text { Software R - } \\
\text { Calculadora }\end{array}$ & Horário \\
\hline$P_{1}$ & $P_{3}$ & $P_{2}$ & $14: 00 \mathrm{~h}$ às 15:00 h \\
\hline$P_{3}$ & $P_{2}$ & $P_{1}$ & $15: 00 \mathrm{~h}$ às $16: 00 \mathrm{~h}$ \\
\hline$P_{2}$ & $P_{1}$ & $P_{3}$ & $16: 00 \mathrm{~h}$ às $17: 00 \mathrm{~h}$ \\
\hline
\end{tabular}

$\mathrm{Na}$ atividade final os participantes, reunidos novamente, tiveram a oportunidade de expressar suas opiniões sobre toda oficina, registrá-la, respondendo a um questionário sobre suas impressões possibilitando com isso, conhecer a opinião de todos sobre o que foi realizado. A intenção era observar como as metodologias foram recebidas, se foram aproveitadas e qual foi a preferida. Após este momento, foram entregues os certificados de participação.

A segunda oficina em 2017foi exclusivamente com alunos da graduação em Licenciatura em Matemática da UFBA, os alunos integrantes do programa PIBID. Inscreveramse, por meio de e-mail, após convite, um total de 16 alunos. Esta oficina teve uma duração menor 3h, o horário disponível para atividades do PIBID. Com o seguinte roteiro: ao chegarem ao IME, os participantes assinaram TCLE, reponderam um questionário, assistiram um slide com as fórmulas utilizadas para resolução de questões como na metodologia tradicional, foi apresentado os modelos sem muito detalhamento, que já são conhecidos da maioria deles, por serem monitores no LEMA onde utilizam esse material. E ainda, apresentado por slide o software R, com uso como calculadora ou com a linguagem de programação (algoritmo) para o auxílio na resolução de problemas ou na escolha da fórmula adequada para tal. Essa parte de apresentação durou 1h, em seguida começou a oficina segundo o método DQL.

A opção de inserir a linguagem de programação com a construção de algoritmo para auxiliar na decisão de qual fórmula foi acrescentada após a primeira oficina, visto a necessidade de entendimento da questão e uso de algoritmo, já que este é um dos pilares da habilidades do RC a ser trabalhado. Na primeira oficina foi percebida também a dificuldade em decidir qual a melhor fórmula para resolução das questões. Para o entendimento de linguagem de programação e utilização do algoritmo, foi apresentada uma 
VI Congresso Brasileiro de Informática na Educação (CBIE 2017)

Anais do XXIII Workshop de Informática na Escola (WIE 2017)

árvore de tomada de decisão com três perguntas norteadoras (o número de objetos é igual ao número de posições, a ordem importa e tem reposição), onde a ordem dessas perguntas pode ser aleatória, trabalhando assim a decomposição e composição, outro pilar das habilidades do RC. Estas atividades foram fundamentais na interpretação, no entendimento e na resolução dos exercícios.

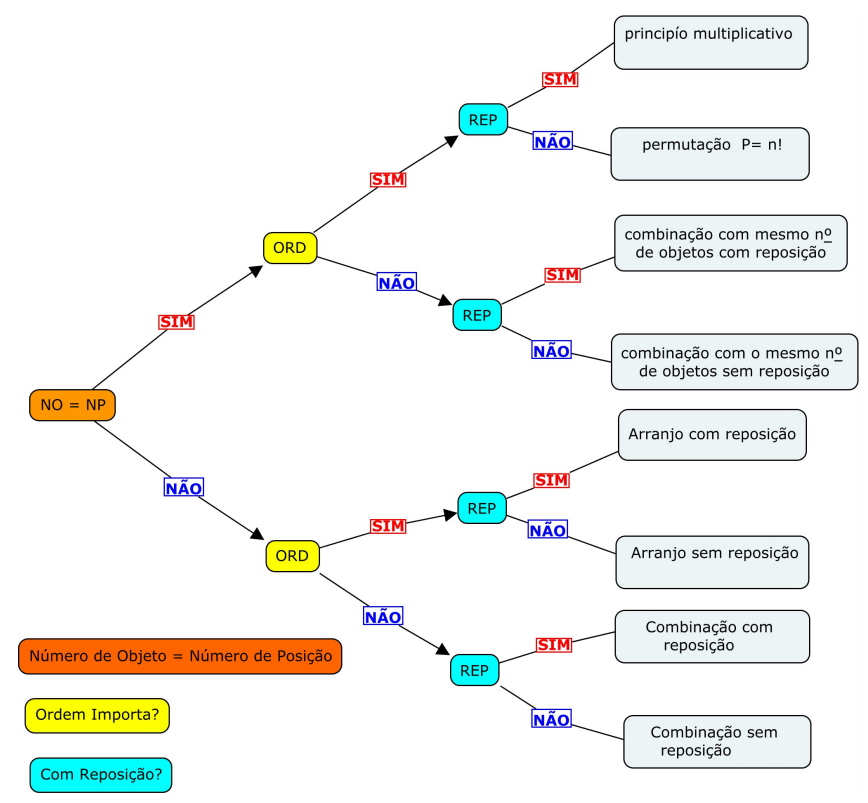

Figura 1. Árvore para tomada de decisão.

A partir da Figura 1, o aluno respondeu às questões apresentadas pelo algoritmo, aplicando os conceitos auxíliados pelos monitores, como a atribuição de operadores lógicos, com os quais interpretaram e resolveram os exercícios propostos.

Os 16 alunos participantes foram agrupados em 4 grupos, e distribuídos em 4 salas, de acordo com o método DQL com duração de 25 min para cada momento.O desenvolvimento foi similar à outra oficina. Foi acrescentada mais uma etapa metodológica e, assim, foi necessário formar mais um grupo de participantes totalizando 4 permutações, para a aplicação do delineamento do DQL com a forma 4 x 4.

Ao final do rodízio, os alunos se reuniram em um espaço comum no IME, onde responderam um questionário sobre a impressão da oficina e elencassem qual metodologia apresentou maior dificuldade. Após isso foram entregues os certificados.

\section{Levantamento de Dados Parciais}

Segue análise da primeira oficina com 43 professores, a partir de quastionário com questões direcionadas para conhecer a satisfação e interesse dos professores: observou-se que os professores participantes tiveram boa aceitação em relação à Oficina de Análise Combinatória e Probabilidade, 55\% avaliaram a interação com o software R como excelente, $86 \%$ manifestaram interesse em participar de novas oficinas de Análise Combinatória e Probabilidade. Eles tiveram $76 \%$ de acerto nas questões sendo maior desempenho na metodologia construtivista com apoio dos modelos. Foi percebido ao final da oficina, que as habilidades do RC estavam presentes em todas as fases e em todas as metodologias aplicadas na Oficina. 
VI Congresso Brasileiro de Informática na Educação (CBIE 2017)

Anais do XXIII Workshop de Informática na Escola (WIE 2017)

Notou-se também que os participantes avaliaram positivamente a aplicação do software R, principalmente quando os erros eram apresentados nos cálculos, possibilitando uma nova tentativa de solução da questão.

Diante das preferências dos professores, ficou claro o interesse em inserir as metodologias construtivista e linguagem computacional com o software $\mathrm{R}$ no dia a dia das salas de aula, amparados pela metodologia tradicional para a construção dos conceitos Análise Combinatória e Probabilidade.

Na segunda oficina que foi feita com os alunos Licenciatura em Matemática, analisando o perfil dos participantes $56,25 \%$ estão matriculados até o $3^{\circ}$ semestre, com idade variando entre 19 e 45 anos e uma média de 28 anos. Com 93,75\% dos participantes oriundos do Ensino Fundamental de escola pública e 50\% vindos Ensino médio público. Sendo que apenas $25 \%$ tiveram contato com o conteúdo Análise Combinatória e Probabilidade quando alunos em de escolas públicas. Com relação à dificuldade de aprendizagem, 68,75\% disseram que não a tiveram, e relataram que a metodologia utilizada quando ainda estudantes da Educação básica era inadequada, percebendo de forma positiva as atividades da oficina, o estímulo e a influência do RC e as suas habilidades em cada fase aplicada. Ainda reconheceram que a árvore de tomada de decisão, o algoritmo e os modelos favoreceram o entendimento e a resolução das questões.

Perguntado aos licenciandos se o algum de seus professores já utilizou algum recurso metodológico em aula, 87,5\% disseram que não no Ensino Fundamental, 75\% no Ensino Médio e 50\% no Ensino Superior.

Após a oficina, foi identificado que 50\% dos licenciandos aprovaram a atividade software $\mathrm{r}$ (calculadora e algoritmo), 44,5\% a metodologia construtivista e 5,5\% a metodologia tradicional. Prometendo que ao serem professores usarão as atividades com as habilidades do RC, adequando-as quando necessário.

O desempenho relacionado aos acertos das questões durante a oficina mostraram que os licenciandos em matemática tiveram dificuldades interpretar e resolver os exercícios, escolher as fórmulas a serem aplicadas nas questões, decompor e compor os dados, abstrair para chegar a uma solução adequada.

\section{Considerações Finais}

A análise dos dados foi realizada a partir de um questionário aplicado aos participantes, concentrando-se em questões relevantes para conhecer a satisfação e interesse dos professores. Ao analisar os resultados e, principalmente, quando consideramos as questões que permearam todas as metodologias, notamos um interesse por inserir novas metodologias no cotidiano das salas de aula para um maior entendimento do conceito de Análise Combinatória e Probabilidade, uma vez que a avaliação da Oficina pelos professores foi satisfatória.

Notamos que o uso do software R despertou o interesse por parte dos participantes, tornando os comandos e as aplicações das fórmulas como algo significativo para aprendizagem. Foi relevante o contato através de simulações e a experimentação que ocorreu com o manuseio dos modelos durante a Metodologia Construtivista, possibilitando o amadurecimento dos conceitos, uma vez que a maioria dos professores já dominavam a teoria, afastando um pouco o abstrato e obtendo novas metodologias de ensino com maior ênfase 
VI Congresso Brasileiro de Informática na Educação (CBIE 2017)

Anais do XXIII Workshop de Informática na Escola (WIE 2017)

para a interpretação do problema.

Esses resultados indicam que a utilização de recursos como os apresentados nas oficinas podem se tornar um importante recurso pedagógico para que os professores trabalhem conceitos de Análise Combinatória e Probabilidade na Educação Básica, passando a encantar o aluno e ganhando contornos diferenciados quando novas metodologias são propostas.

Os resultados obtidos nas Oficinas de Análise Combinatória e Probabilidade, confirmam que o uso de recursos na cosntrução de conhecimento é valido, já que a experiência proporcionou aos professores em exercício e aos alunos em formação, reflexões mais abrangentes em relação ao conceito de Análise Combinatória e Probabilidade por meio de uma visão diferenciada do uso da linguagem de programação e do software R. Além disso, no geral pode ser dito que os resultados demonstraram que há interesse na aplicação das novas metodologias como recurso pedagógico. Neste esteio, o trabalho com os modelos construtivista e a linguagem de programação com o software R mostrou que a experimentação, os comandos e as aplicações das fórmulas podem ser algo significativo para a aprendizagem.

\section{Referências}

Brackmann, C., Barone, D., Casali, A., Boucinha, R., and Muñoz-Hernandez, S. (2016). Computational thinking: Panorama of the americas. In Computers in Education (SIIE), 2016 International Symposium on, pages 1-6. IEEE.

Cazorla, I. M. and SANTANA, E. R. d. S. (2006). Tratamento da informação para o ensino fundamental e médio. Série Alfabetização Matemática, Estatística e científica. Itabuna, Editora Via Literum.

da Serra Costa, J. F., Correia, M. G., and de Souza, L. T. T. (2011). Utilização do método de análise hierárquica na escolha de software estatístico para a demanda de uma universidade pública. Produto \& Produção, 12(1):42-59.

Ferreira, A. C., Melhor, A., Barreto, J., de Paiva, L. F., and Matos, E. (2015). Experiência prática interdisciplinar do raciocínio computacional em atividades de computação desplugada na educação básica. In Anais do Workshop de Informática na Escola, volume 21, page 256.

PANAINO, R. (1998). Estatística no Ensino Fundamental: Uma Proposta. de Inclusão de Conteúdos Matemáticos. PhD thesis, Dissertação de Mestrado, UNESP, Rio Claro-SP.

Papert, S. (1980). Mindstorms: Children, computers, and powerful ideas. Basic Books, Inc.

PIMENTEL-GOMES, F. (1990). Curso de estatística experimental. Piracicaba: Nobel.

Wing, J. M. (2006). Computational thinking. Communications of the ACM, 49(3):33-35. 